\title{
The 21st Century Cures Act Implications for the Reduction of Racial Health Disparities in the US Criminal Justice System: a Public Health Approach
}

\author{
Donna M. Cole ${ }^{1}$ Dawna Marie Thomas ${ }^{2} \cdot$ Kelsi Field $^{3} \cdot$ Amelia Wool $^{3}$. \\ Taryn Lipiner $^{3}$ • Natalie Massenberg ${ }^{4}$ - Barbara J. Guthrie ${ }^{5}$
}

Received: 23 June 2017 / Revised: 8 September 2017 / Accepted: 25 September 2017 /Published online: 9 November 2017

(C) W. Montague Cobb-NMA Health Institute 2017

\begin{abstract}
Past drug epidemics have disproportionately criminalized drug addiction among African Americans, leading to disparate health outcomes, increased rates of HIV/AIDS, and mass incarceration. Conversely, the current opioid addiction crisis in the USA focuses primarily on white communities and is being addressed as a public health problem. The 21st Century Cures Act has the potential to reduce racial health disparities in the criminal justice system through the Act's public health approach to addiction and mental health issues. The 21st Century Cures Act is a progressive step in the right direction; however, given the historical context of segregation and the criminalization of drug addiction among African Americans, the goals of health equity are at risk of being compromised. This paper discusses the implications of this landmark legislation and its potential to decrease racial health disparities, highlighting the importance of ensuring that access to treatment and alternatives to incarceration must include communities of color. In this paper, the authors explain the key components of the 21st Century Cures Act that are specific to criminal justice reform, including a key objective, which is treatment over incarceration. We suggest that without proper attention to how, and where, funding mechanisms are
\end{abstract}

Donna M. Cole

donna.cole@yale.edu

1 Center for Interdisciplinary Research on AIDS, Yale School of Public Health, New Haven, CT 06510, USA

2 Simmons College Department of Sociology, Women and Gender Studies, Boston, Massachusetts 02115, USA

3 Simmons College Department of Public Health, Boston, MA, USA

4 Icahn School of Medicine at Mount Sinai, New York, NY, USA

5 Northeastern University School of Nursing, Boston, MA, USA distributed, the 21st Century Cures Act has the potential to increase racial health disparities rather than alleviate them.

Keywords 21st Century Cures Act · Health disparities · Mental illness $\cdot$ Substance abuse $\cdot$ HIV/AIDS $\cdot$ Mass incarceration

\section{Introduction}

The 21st Century Cures Act (Cures Act) was signed into law on December 13, 2016 by President Barack Obama [1]. Obama approved the legislation after the Cures Act received strong congressional support from a majority of Democrats and Republicans in the House and Senate. The Cures Act aims to improve health outcomes for vulnerable populations, including individuals with mental illness and substance abuse disorders, and those who have recently been released from prison. Racial disparities in the criminal justice system have been well documented, demonstrating that communities of color experience harsher treatment than their White counterparts [2-5]. Current research suggests that the USA is experiencing a growing opioid addiction crisis, with high prevalence in predominantly White middle-class and suburban communities. As a result, substance abuse is no longer perceived as a problem limited to urban communities. The Cures Act encourages the decriminalization of substance abuse, offering a public health approach, and engendering the potential to address the racial disparities present in the criminal justice system. The goals of this paper are to provide an analysis of this key legislation, a historical perspective of substance abuse, and an analysis of how the 21st Century Cures Act aims to alleviate the criminalization of substance abuse. Our analysis includes an examination of how countries outside of the USA have used public health approaches as 
alternatives to incarceration for those with drug addiction. The 21st Century Cures Act has the potential to reduce racial disparities among communities of color who have been disproportionately incarcerated, and thus, we recommend that legislators, providers, advocates, and members of the judiciary pay great attention to how funding is allocated.

\section{Overview and Key Elements}

The Cures Act provides broad legal guidelines based on the revision and expansion of key substance abuse legislation and is designed to improve health and treatment outcomes for people suffering from mental illness and substance abuse. Important legislation on which the Cures Act builds includes the Comprehensive Addiction and Recovery Act of 2016 [6] and the Omnibus Crime Control and Safe Streets Act of 1968 [7]. The Cures Act aims to provide outpatient treatment to clients who are not residing in a correctional or inpatient treatment facility. Eighteen legislative titles specific to criminal justice reform are included in the Act, such as Title XIV Mental Health and Safe Communities, which includes sections 14002, 14003, 14006, 14009, 14012, and 14013, and Subtitle B of Title XIV Comprehensive Justice and Mental Health, which includes sections 14016 and 14022 (see Table 1). The Act encourages courts to sentence offenders to treatment, rather than incarceration, and promotes alternatives to the warehousing of mentally ill individuals and those suffering from drug addiction in state and federal jails and prisons. Furthermore, the Act calls for new spending of one billion dollars in grants to states to provide treatment to those suffering from opioid addiction and provides funding and training for law enforcement officers and judicial and criminal justice officials on effective strategies for responding to clients with mental illness and substance abuse disorders. Additional provisions focus on assisting offenders with a wide range of social services and support mechanisms, such as behavioral health services, transitional services, mental health treatment, housing to alleviate homelessness, education and training opportunities, support for family members, and the development of partnerships with law enforcement (see Table 1).

\section{Criminalizing Drug Addiction Among African Americans}

A significant objective of the Cures Act is to offer alternative drug treatment intervention, rather than prison, for those with drug addiction and mental illness and to provide those recently released from prison with an opportunity to rebuild their lives through effective treatment management. In the spirit of the law, mental health courts will provide a public health approach to offenders with substance abuse and mental health issues [1].
The USA is currently facing a growing opioid addiction crisis, with a high prevalence of substance abuse among White middle-class populations in suburban communities. Addiction has now surpassed the prevalence of cancer in the USA. Opiate abuse, including heroin, fentanyl, and prescription pills, has increased drastically in recent years [8]. In 2015, death due to heroin use was more common than gun-related deaths [9]. According to The Centers for Disease Control, deaths from drug overdose have increased significantly since 2000. In 2015 , over 33,000 deaths were caused by drug overdose [10]. A significant portion of the Cures Act addresses this opioid addiction epidemic and thus the predominantly White communities in which the crisis is occurring. In a clear departure from earlier attempts to address addiction in communities of color, however, the Cures Act aims to provide treatment for individuals coping with addiction.

Yet, the current opioid epidemic bears striking parallels to the crack epidemic that impacted African American communities during and since the 1980s. Instead of being offered treatment, however, crack substance abuse victims were, and continue to be, criminalized. The criminalization of substance abuse disorders in African American communities has resulted in numerous adverse health outcomes, including increased rates of infectious diseases across affected populations [11-14]. A key driver of the HIV/AIDS epidemic among African Americans is substance abuse. In addition, increased rates of hepatitis $\mathrm{C}$ and sexually transmitted infections are correlated with substance use disorders $[2,15]$. Furthermore, the criminal justice approach has also led to criminal charges for drug-related offenses and the mass incarceration of African Americans, providing a stark contrast to the Cures Act's public health focus [16]. President Nixon's "War on Drugs" increased the presence of drug control agencies and police surveillance while advancing mandatory sentences for drug offenses [3]. Racial bias has had a longstanding and significant impact on narcotics law enforcement, which has adversely influenced the public's perception and societal response to substance abuse among African Americans. African Americans are disproportionately represented in the criminal justice system, both as offenders and victims, relative to their numbers in the general population. Among drug offenders, African Americans are disproportionately arrested, convicted, and incarcerated on drug charges $[3,17]$.

\section{Racial Disparities in the Criminal Justice System}

The US criminal justice system is plagued by racial disparities in both federal and state courts [16, 17]. These disparities are historical, structural, and systemic - beginning long before an individual finds himself or herself in custody or in front of a judge. For many African American and Latinx populations, poverty is a common characteristic of their neighborhoods [18]. Racial residential segregation is also a common and 
Table 1 Mental health and safe communities and comprehensive justice and mental health objectives

Section Objectives

Section 14002 Alternatives to Incarceration

Section 14003 Mental Health Court

Section 14006 Assistance for Individuals Transitioning Out of Systems

Section 14009 Advancing mental health as part of offender reentry

Section 14012 Co-occurring Substance Abuse and Mental Health Challenges in Residential Substance Abuse Treatment Programs

Section 14013 includes Section 2901 Mental Health and Drug Treatment Alternatives to Incarceration Programs. Amends the Omnibus Crime Control and Safe Streets Act of 1968

Section 14014 amends the Omnibus Crime Control and Safe Streets Act of 1968 and includes Section 2992 National Criminal Justice and Mental Health Training and Technical Assistance

Subtitle B of Title XIV Comprehensive Justice and Mental Health includes section 14016 Reports on the Number of Mentally Ill Offenders in Prison

Subtitle B of Title XIV Comprehensive Justice and Mental Health includes section 14022 Prisons and Jails authorizes the Attorney General
To create court-ordered outpatient treatment programs as alternatives to incarceration

To create federal mental health court pilot program to serve as alternative to incarceration for low-level offenders

Increase access to intensive behavioral health services to prevent relapse, incarceration, suicide and violent behavior while providing the patient with an alternative to a restrictive environment, involuntary inpatient treatment or incarceration. Provide transitional services and mental health treatment to individuals with co-occurring disorders and mental illness, including housing placement and other forms of transition assistance.

Target and treat offenders who suffer with a history of mental illness, substance abuse and homelessness. Prior to release from prison, assessments will be conducted on the housing status and social support systems of individuals to assist with their transition back into the community.

Establish and implement specialized residential substance abuse treatment programs for individuals who suffer with co-existing substance abuse and mental health disorders. This section may make grants to eligible participants to develop, implement, or expand treatment alternatives to incarceration. Also, place individuals with co-occurring mental illness and substance use disorder into appropriate and approved programs prior to arrest.

Divert eligible participants, those with non-violent offenses, a history of current substance use disorder, mental illness or co-occurring mental illness and substance use disorder away from correctional institutions and into approved programs funded by this section (42 U.S.C. § 14013).

Grant funding for technical assistance and training in mental health, crisis intervention services, and criminal justice and law enforcement. This section is to provide support and education to people with mental illness and to extend support to the families of those who suffer from mental health disorders.

Improve reporting of individuals who suffer from serious mental illness (42 U.S.C. § 14016). Provide Congress with a cost estimate of the numbers of people incarcerated who suffer from mental illness. This estimate should be provided to Congress within 12 months of enactment of the legislation.

Grant funding to produce correctional facility programming that is directed toward the reduction of recidivism upon offender release (42 U.S.C. § 14002). Periodic assessments of the clinical, medical and social needs of inmates, the development of post-release transition plans for eligible inmates, and training for correctional facility staff to identify and respond to mental health or co-occurring mental health and substance abuse disorders.

Source: Description of sections from the 21st Century Cures Act and how it relates to various provisions and titles of other laws

accepted aspect of American life, leading to concentrated poverty in certain areas. This concentrated poverty, also termed "neighborhood disadvantage," is responsible for adverse health and education outcomes, lowered access to employment, and increased rates of incarceration [4, 19-21]. Segregated communities are especially vulnerable to police, since they often lack the resources to advocate for protection. Police contact and interrogation is routine and accepted for some, if not most, residents. Young Black men often submit to unlawful searches with no knowledge of the Fourth
Amendment, ${ }^{1}$ and if they fail to comply with unlawful instructions, they are charged with resisting arrest or obstruction of justice $[22,23]$. In areas permitting stop-and-frisk policy,

\footnotetext{
${ }^{1}$ The Fourth Amendment of the U.S. Constitution provides that the right of the people to be secure in their persons, houses, papers, and effects, against unreasonable searches and seizures, shall not be violated, and no Warrants shall issue, but upon probable cause, supported by Oath or affirmation, and particularly describing the place to be searched, and the persons or things to be seized.
} 
more African American and Latinx people are stopped at "random" than Whites. For example, in New York City, $52 \%$ of those stopped by police in 2016 were African Americans. European Americans were detained by police in $10 \%$ of cases, while $29 \%$ of Latinx were stopped [5]. This data highlights the implicit racial profiling that occurs when law enforcement officers are encouraged to stop persons they consider to be a danger to the community.

According to a 2014 report by the American Civil Liberties Union (ACLU), similar racial disparities exist at all levels of the criminal justice system, demonstrated by number of arrests, defendants' prosecution and charge(s), plea negotiation, trials, and sentencing [3, 24]. For example, racial disparities in sentencing are endemic in the criminal justice system. Sentences imposed on Black men in the federal system are approximately $20 \%$ longer than those of Whites who were convicted of similar crimes, and disparities increase as sentence length increases [24]. During the sentencing process, prosecutors have a vast amount of discretion at both the federal and state levels in determining the types of criminal charges they will file. Prosecutors frequently file criminal charges contaminated with racial bias. European Americans are less likely to be charged with offenses that result in terms of imprisonment and are more likely to receive plea agreements offering the defendant fines and/or probation with no recommendation for custody [25]. Furthermore, after controlling for offense characteristics, criminal history, defense counsel type, age of the offender, offender's educational attainment, and crime/economic characteristics of the jurisdiction, researchers have found that federal prosecutors charge African Americans with crimes carrying longer sentences than the crimes with which they charge Whites [25]. According to ACLU director Monica Hopkins, mandatory minimum sentences often "tie and hamstring the hands of federal judges," and as a result, judges often accept the sentencing recommendation of the prosecutors, sentencing African Americans more harshly than other racial/ethnic groups [22].

While much of the legislation under which African Americans are sentenced is race neutral in language, research suggests that not only the outcomes, but also the intent, of the legislation disproportionately targets African Americans over Whites [3]. A prime example of seemingly race-neutral sentencing legislation is the differentiation between crack cocaine, which is often associated with African Americans, and powder cocaine, which is frequently associated with Whites, in federal sentences. Prior to 2010, legislation imposed harsher sentences for crack cocaine over powder cocaine at a ratio of 100:1. In 2010, the Fair Sentencing Act decreased the ratio to $13: 1$; however, disparity remains, despite evidence from scientific communities that has debunked all original rationale for imposing different penalties for the two drugs [26]. Thus, the Fair Sentencing Act remains unfair and continues to disproportionately affect African American offenders. Other legislation that creates sentencing disparities includes sentencing enhancements under three-strike rules and mandatory minimums. These enhancements are made on a state-by-state basis, meaning that in some states, a conviction carries a much greater penalty than in others. Because of this:

If a federal drug conviction involves a particular quantity of drugs (such as $50 \mathrm{~g}$ of methamphetamine, $280 \mathrm{~g}$ of crack cocaine, or $5 \mathrm{~kg}$ of powder cocaine) and the defendant has two prior qualifying drug convictions in state or federal courts, no matter how old those convictions are, he or she must be sentenced to mandatory life without parole [27].

African Americans are more likely to be sentenced at the state and federal levels and are more likely to receive harsher sentences; they are also more likely to be incarcerated in lieu of receiving substance abuse treatment. Research, although limited, shows that treatment for repeat offenders suffering from addiction is more effective in lowering recidivism rates than incarceration [28]. Despite this evidence, African American men are less likely to receive mandated drug treatment as an alternative to incarceration. Specifically, while Blacks and Latinx individuals make up only $35 \%$ of drug treatment admissions, they comprised $60 \%$ of prison admissions in 2008. This is important, as criminal justice referrals made up $37 \%$ of drug treatment admissions in the USA in 2008 [29].

Standing in stark contrast to previous attempts to address addiction in communities of color is the Police Assisted Addiction Recovery Initiative (PAARI), which allows for opioid users to turn in drug paraphernalia and illicit substances and request treatment at the police station [30]. This program began in Gloucester, a predominantly White city in Massachusetts. While PAARI has been very successful in providing treatment rather than incarceration to Gloucester residents, these options are not available for addicts in communities of color, furthering racial disparities.

Considering the history and current evidence of racial disparities in the criminal justice system, it is important that the funding of the Cures Act be dispersed by states in an equitable way in order to eliminate racial disparities. It is crucial that criminal justice professionals use tools to both detect and reduce the impact of implicit racial bias, and that policymakers help to curb excessive incarceration by developing policies that aim to reduce disparities that are present in sentencing and in pursuing charges against African Americans [31].

\section{Racial Residential Segregation Impacts Health}

Researchers note that racial and ethnic segregation negatively impacts the health of individuals and is a major factor in creating low-opportunity communities [19, 21, 32]. Areas considered "low opportunity" are more likely to have limited resources, services, and opportunities [18]. Business owners 
are reluctant to set up shops in low-opportunity communities, which results in lowered availability of supermarkets and limitations in the built environment that provides safety and wellness. Low-opportunity communities have inadequate schools, lack of business presence, limited job prospects or lower levels of employment, and inadequate and inaccessible healthcare services. Thus, living in low-opportunity communities can be considered a social determinant of health, limiting opportunities for individuals to gain socio-economic mobility and satisfactory educational attainment.

African Americans and Latinx populations are disproportionally represented in low-opportunity communities. For example, in 2014, the Connecticut Association for Human Services reported that $81 \%$ of African Americans/Blacks and $79 \%$ of Hispanics/Latinx resided in "low opportunity" areas across the state, compared to $26 \%$ of European Americans/Whites [3]. The report also highlights the areas in which the racial makeup is disproportionately White, many of which have been identified as "very high opportunity" and "high opportunity." Notably, Connecticut is not unusual in this respect, but rather representative of an increasing phenomenon across the USA.

In addition, the social determinants of low-opportunity communities, combined with the higher levels of poverty in predominantly African American/Black and Hispanic/Latinx neighborhoods, lead to adverse health outcomes for many residents. African Americans have disproportionate adverse health outcomes across many disease states, including higher rates of chronic illness, stress-related illness, diabetes, stroke, cancer, and heart disease [33]. As previously noted, African Americans also suffer from increased rates of infectious disease burden, including HIV/AIDS, hepatitis C, and sexually transmitted infections. African Americans are most adversely impacted by HIV/AIDS disease burden. The high prevalence of HIV/AIDS among African Americans is correlated with poor mental health, high rates of depression, substance abuse disorder, lowered levels of medication adherence, lowered economic opportunity, and concentrated poverty [15, 32, 34]. Compounding these issues, African Americans are plagued by the lack of access to diagnosis and treatment for mental health issues and substance use disorders.

Residence in a low-opportunity community is an important factor for prisoners dealing with substance abuse and other health problems. Researchers have long cited substance abuse as a risk factor for HIV/AIDS [12]. The criminalization of substance abuse among African Americans has led to an increase in rates of HIV/AIDS-related morbidity, AIDS-related mortality, hepatitis $\mathrm{C}$, and sexually transmitted infection [11-14]. While over half of all prisoners in the USA suffer from mental health disorders, less than one third of inmates receive treatment while they are incarcerated [35]. Since many states are unable to provide mentally ill prisoners with mental health treatment, individuals are often confronted with challenges once they are released back into society as well, placing them at greater risk for recidivism [36]. Upon release, many incarcerated individuals return to low-opportunity communities with worsening mental health conditions and few treatment options, resulting in higher rates of recidivism, social isolation, and low levels of social support. Furthermore, because of the harsh penalties associated with recidivism, the lack of services available to mentally ill and recently released inmates often leads to lengthy sentences. Thus, to avoid recidivism, mental health services should be provided to incarcerated inmates suffering from mental illness, and alternatives to incarceration should be offered for those who suffer from mental illness and substance use disorder.

\section{Improving Health Outcomes Through the Provision of Mental Health Treatment: a Global Analysis}

The USA is one of many countries with a high prevalence of citizens suffering from mental illness and substance use disorders. Research shows that many people who are addicted to drugs also suffer from underlying or undiagnosed mental health issues [37]. Individuals who suffer from mental illness and substance use disorders frequently find themselves in the prison system.

Recent data highlights the prevalence of mentally ill incarcerated individuals in 24 countries [38]. The research was conducted in both the USA and in other countries, and classified mental illness as major depression/depressive disorder, schizophrenia, and bipolar disorder. Norway, New Zealand, Spain, Germany, Hong Kong, and Portugal each have a high prevalence of disease burden, with a significant number of their populations suffering from mental illness, substance abuse, or both. In Europe, institutions for the mentally ill began to close after years of patient abuse, such as unnecessary surgeries, and harmful treatments, including lobotomies. Furthermore, it was later discovered that many of those placed in institutions were not necessarily mentally ill, but social outcasts - persons deemed unacceptable by their families and communities [39]. Unwanted, many of these individuals found themselves segregated, institutionalized, and vulnerable to medical malpractice. After years of deinstitutionalization of mental hospitals, many of those suffering with mental illness now receive care in prisons.

Several countries and administrative regions, including Hong Kong, Germany, Norway, New Zealand, Spain, and Portugal, now use a public health approach to address mental illness and substance abuse, and evidence suggests that these methods lead to improved health outcomes. In Hong Kong, reintegration programs include education and transition assistance with employment opportunities prior to release from prison, while Germany has garnered the attention of 
policymakers in the USA for its progressive approach to criminal justice [40-42]. In Norway, prisoners are identified as members of a disadvantaged population. Thus, prison staff recognize that if a person is considered a danger to the society, that person is in need of treatment, making treatment available to that person upon admission to prison. This system of care involves treatment teams that include psychotherapists, psychologists, occupational therapists, and counselors. The treatment goals include substantive healthcare for individuals while they are in the prison and during their transition back into the community. This is especially important for those with mental health disorders. Adherence to medication and treatment is very important and can be improved through both inpatient and outpatient care and collaboration with community health partners. Overall, Norway aims to improve the quality of prison healthcare to the point where it is equal to that of healthcare received by the general public [43].

New Zealand, which has a high rate of mental illness within its criminal justice system, serves as a further example. By improving its screening and assessment process, the country increased access to referrals and treatment for prisoners, allowing for a more fluid transition for individuals back into the community after they are released [38]. Spain is another country that has created comprehensive addiction and mental health treatment services within its prisons. According to provisions established in the United Nations and the Council of Europe in the 1960s, prison healthcare services must mirror the quality of those that are provided to the general population. These provisions are upheld by the Declaration of Madrid, which was approved unanimously by 65 countries in 2009 with the goal of eliminating health inequities that occur in prisons and especially communicable diseases that threaten the health of the greater public. The countries involved in the Declaration worked together with experts in developing a provision of services to interpret the nations' data on disease transmission in prisons, as well as post-release mortality. Within the Declaration, addiction accompanied by a communicable disease was also addressed, as many communicable illnesses, such as HIV/AIDS, are transmitted as a result of addiction [44]. Overall, the Declaration of Madrid recognized the urgent need to provide mental health services to inmates suffering from mental illness and is perhaps a first step in creating comprehensive mental healthcare in prisons across Europe.

Utilizing a differing approach, Portugal has decriminalized the use, possession, and acquisition of illicit substances for personal use, defining "personal use" as a ten-or-fewer-day supply of a substance [45]. Rather than incarcerating drug users, Portugal established a system to refer addicts to the Commissions for the Dissuasion of Drug Addiction (CDT) centers. CDT centers are three-person panels, composed of social workers, legal advisors, and medical professionals, located throughout the country. Rather than bringing drug users to jail, police order addicts to report to CDT centers within 72 hours of their offense. Police have also shifted their focus from users, to those proliferating substances and profiting from addiction. As a result, Portugal has seen a significant increase in the number of drug users entering treatment from 1998 to 2003 [45]. Additionally, drug-related deaths and diseases, including HIV and hepatitis C and B, decreased during this same time period. As a result of decriminalization, overcrowding issues in prisons resolved, and the financial and bureaucratic costs of imprisoning drug addicts decreased, allowing more resources to be utilized to eliminate drug trafficking. In sum, Portugal's decriminalization of the use, possession, and acquisition of illicit substances for personal use has allowed the country to provide treatment to addicts and decrease drug trafficking simultaneously, benefitting society as a whole.

Improving client service delivery of community support services and increasing programs that address mental health disorders can alleviate substance abuse disorder and increase resources currently available to the mentally ill. Data shows that inmates in the USA suffering from mental illness are the least likely to receive treatment while incarcerated [46]. For people recently released from prison who suffer from mental health disorders, homelessness increases recidivism and serves as a barrier to medication compliance. Mental illness, including schizophrenia, a history of arrests, male gender, race, and younger age are all risk factors for re-arrest [47].

Case management or medical services for individuals released from jail are strongly associated with reduced risk for re-arrest [28]. Of critical importance is the need for mental health treatment among populations vulnerable to re-arrest and incarceration. Mental health courts can also play a valuable role by improving coordination with community health partners, providing alternatives to incarceration, and assisting those recently released from prison [48].

\section{The Importance of Community-Based Interventions and Support Services}

According to Rosenberg, one of the defining characteristics of an epidemic is the social agreement that the epidemic is unavoidable and that communities must act to intervene before an epidemic gets worse. In an epidemic, the bodies must accumulate and the sick must suffer in increasing numbers before officials acknowledge what can no longer be ignored [49]. The USA has historically failed to acknowledge the existence of adverse health outcomes among African Americans, leading to what W.E.B. $\mathrm{Du}$ Bois once termed "a peculiar indifference" [50]. While the opioid addiction crisis among Whites/ European Americans has been treated as a public health 
concern with a call for treatment and rehabilitation, African American drug addiction has been addressed as a criminal justice issue with harsh penalties for drug possession, use, and distribution. In theory, the Cures Act can reduce racial health disparities by providing comprehensive treatment options for all people who suffer from drug addiction, mental health disorders, and co-occurring disorders.

The overarching aim of the Cures Act is to provide recently released inmates with opportunities for treatment and rehabilitation. Since many incarcerated individuals are from low-opportunity areas, providers and prison officials should be aware of the challenges facing those recently released from jails and prisons as they attempt to transition back into a community with limited resources, employment, and opportunities for education. Prisons and jails should work in partnership with employers and area educational institutions to provide transition assistance to improve support networks and treatment for recently released inmates. The Cures Act also intends to increase healthcare access among people suffering from mental health and substance use disorders. In order to accomplish this goal, community partners must work in collaboration with prisons and jails to improve healthcare access for people suffering from co-occurring substance use disorders and mental illness, as medication adherence is extremely important in the prevention of involuntary hospitalization or incarceration.

\section{Transition Assistance for Individuals Returning to the Community After Release from Prison}

Additionally, the role of employers in low-opportunity areas is critical in reducing recidivism and promoting wellness. Prisons and jails should provide training and education to meet the needs of the workforce so that individuals will have access to employment opportunities post-release. Probation officers have overwhelming workloads that include dozens of people with post-release conditions who require employment. Prisons and jails should aim to strengthen employer capacity to hire and train recently released inmates and work in collaboration with employers to promote wellness initiatives within the workplace.

The role of stigma is another key component in increased recidivism rates. Stigma has an adverse impact on mental health. Researchers note that public stigma can include negative perceptions of people with mental illness and that this stigma is internalized, leading to "self-stigma"; self-stigma can lead to low self-esteem, lowered levels of social cohesion, and poor health [51-53]. Researchers have found that "self-stigma" can have negative impacts on recently released inmates as they attempt to reintegrate into their communities [54]. Former inmates often return to their communities unable to escape the negative perceptions associated with those who have had contact with the criminal justice system. Often, the primary measure of the success of an individual upon release from prison is recidivism. Another way of measuring success, however, would be to consider a former inmate's levels of social support, self-esteem, and ability to plan and look forward to the future. Correctional education can play a vital role in preparing offenders for re-entry to the community. For example, in Hong Kong, corrections authorities promote the reintegration of offenders by hosting education programs and organizing job fairs in prisons [40]. For many released offenders, acceptance comes from those who have had similar experiences with the criminal justice system. Unfortunately, to affiliate with former inmates is always in violation of court directives. In order to change this, the community must alter its views of persons involved with the criminal justice system. Healthcare providers, social workers, judicial officers, and court personnel should work in collaboration with each other to promote wellness and alternatives to incarceration for all Americans.

The section of the Cures Act with the most potential to reduce racial disparities in the criminal justice system is section 14013-Mental Health and Drug Treatment Alternatives to Incarceration Programs-which gives the Attorney General the authority to grant funds to states to achieve those aims. However, there is no specific language within the section of the Act that guarantees that these alternatives to incarceration programs will actually be created and implemented in ways that alleviate racial disparities. The section specifies that "eligible participants" in these programs would be offenders who have not been convicted of crimes of violence or serious drug offenses as outlined in title 18 U.S.C. section 924 [53]. Importantly, African American and Latinx individuals are disproportionately arrested for violent crimes, which would limit their ability to benefit from programs designed in the states [55]. Thus, this section of the Act should be amended to include all offenders in need of mental health and substance abuse treatment.

After the passing of the Cures Act, policymakers in different states indicated varying priorities, many of which would limit the ability of minority groups to benefit from the legislation. While states that have been hit the hardest by the opioid crisis will receive the largest portion of funds under the Cures Act, drug addiction plagued numerous communities prior to the opioid crisis [56]. Past drug epidemics, like the crack cocaine epidemic of the 1980s, demonstrate the consequences of racially discriminatory enforcement of drug legislation and policy. New Hampshire has the fourth highest population percentage of Whites (96\%) and suffers some of the highest 
mortality rates due to drug overdose of any US state [57]. Maine, too, is at least $96 \%$ White, and according to The Portland Press Herald, would receive enough funding from the 21st Century Cures Act to expand coverage to 25-30,000 individuals who lack access to drug treatment across the state [58].

We strongly recommend that the funding mechanisms of the Cures Act be assessed to ensure that all persons are able to benefit from the improvements in addiction and mental health treatment included in the law to be certain that we are not racializing addiction in the USA. Without careful attention to the funding mechanisms included in this legislation, the Cures Act has the potential to exacerbate racial disparities rather than alleviate them. The 21st Century Cures Act is a step in the right direction in the USA, as it is the first legislative attempt to decriminalize addiction through the offering of recovery initiatives. Toward this end, the Cures Act takes a public health approach to mental health and addiction, expanding treatment and alternatives to incarceration and serving as a clear departure from the criminal justice approach. Without legislative focus on alleviating the racial disparities created by the criminal justice approach, however, the 21 st Century Cures Act could potentially result in the continuation of racial inequity in health and justice.

Acknowledgements The authors are grateful to the participants of the pilot study "The Role of Illness Representation on ART Adherence Among African American Women" (R25MH087217 Guthrie and Schensul PIs), funded by the National Institute of Mental Health, which served as the basis for this research. Special thanks to Dr. Trace Kershaw, Dr. Jean Schensul, REIDS, Yale School of Public Health, Center for Interdisciplinary Research on AIDS (CIRA), and Elaine O'Keefe. The content is solely the responsibility of the authors and does not necessarily represent the official views of the National Institute of Mental Health or the National Institutes of Health.

Funding This research was funded by the National Institute of Mental Health (R25MH087217).

\section{Compliance with Ethical Standards}

Conflict of Interest The authors declare that they have no conflict of interest.

\section{References}

1. 21st Century Cures Act. 2015-2016; $114^{\text {th }}$ Congress HR 6 .

2. Wood E, Kerr T, Small W, Li K, Marsh DC, Montaner JSG, et al. Changes in public order after the opening of a medically supervised safer injecting facility for illicit injection drug users. Can Med Assoc J. 2004;17(7):731-4.

3. Nunn KB. Race, crime and the pool of surplus criminality: or why the "war on drugs" was a "war on blacks.". Gender Race Just. 2002:381-445.

4. Latkin CA, German D, Vlahov D, Galea S. Neighborhoods and HIV: a social ecological approach to prevention and care. Am Psychol. 2016;68(4):210-24.
5. New York Civil Liberties Union. Stop-and-Frisk Data. 2017. https://www.nyclu.org/en/stop-and-frisk-data.

6. Comprehensive Addiction and Recovery Act. 2016; 114th Congress H.R. 2.

7. The Omnibus Crime Control and Safe Streets Act of 196842 U.S.C 3789D.

8. Wing N. America, it's time for an intervention: drug overdoses are killing more people than cars, guns. HuffingtonPost.com. 2013. http://www.huffingtonpost.com/2013/08/30/drug-overdosedeaths_n_3843690.html.

9. Rudd RA, Seth P, Felicita D, Scholl L. Morbidity and mortality weekly report. Centers for Disease Control and Prevention 2016. https://www.cdc.gov/mmwr/volumes/65/wr/mm655051e1.htm.

10. Centers for Disease Control and Prevention. Opioid Overdose. 2016. https://www.cdc.gov/drugoverdose/data/statedeaths.html.

11. Rubenstein LS, Amon JJ, McLemore M, Eba P, Dolan K, Lines R, et al. HIV, prisoners, and human rights. Lancet. 2016;388(10050): 1202-14.

12. Lichtenstein B. Drugs, incarceration, and HIV/AIDS among African American men: a critical literature review and call to action. Am J of Men's Health. 2009;3(3):252-64.

13. Lemelle AJ. Linking the structure of African American criminalization to the spread of HIV/AIDS. J Contemp Crim Just. 2016;19(3):270-92.

14. Hendricks L, Wilson A. The impact of crack cocaine on Black America. Nat Forum J Counsel Addict. 2013;2(1):1-5.

15. Friedman SR, Cooper HLF, Osborne AH. Structural and social contexts of HIV risk among African Americans. Am J Public Health. 2009;99(6):1002-8.

16. Alexander M. The new Jim Crow: mass incarceration in the age of colorblindness. New York: The New Press; 2012.

17. Fellner J. Race and drugs. Oxford Handb Online. 2013; https://doi. org/10.1093/oxfordhb/9780199859016.013.007.

18. Carroll J. Opportunity in Connecticut: the impact of race, poverty and education on family economic success. Connecticut Association for Human Services: Hartford; 2012. http://www. racialequitytools.org/resourcefiles/OpportunityInCT.pdf

19. Williams DR, Collins C. Racial residential segregation: a fundamental cause of racial disparities in health. Public Health Rep. 2001;116(5):404-16.

20. Pattillo M, Western B, Weiman D. Imprisoning America: the social effects of mass incarceration. New York: Russell Sage Foundation; 2006.

21. Brawner BM. A multilevel understanding of HIV/AIDS disease burden among African American women. J Obstet Gynecol Neonatal Nurs. 2014;43(5):633-E50.

22. AU Library. Exploring social justice: racial disparities and the criminal justice system. 2017. https://www.youtube.com/watch?v= FaCw_TBiEHw.

23. U.S. Const. amend. IV.

24. American Civil Liberties Union. Racial Disparities in Sentencing. Written Submission to the Inter-American Commission on Human Rights. Hearing on Reports of Racism in the Justice System of the U.S. 2014.

25. Starr SB, Rehavi MM. Racial Disparity in Federal Criminal Charging and its Sentencing Consequences. University Of Michigan Law \& Econ, Empirical Legal Studies Center Paper. 2012; NO 12-002.

26. Coyle M. Race and class penalties in crack cocaine sentencing. Paper presented at the annual meeting of the American Sociological Association, Atlanta Hilton Hotel, Atlanta, GA. 2003. http://www.allacademic.com/meta/p106700_index.html.

27. Russell SF. Rethinking recidivist enhancements: the role of prior drug convictions in federal sentencing. 43 U.C. Davis L. Rev. 2010;1135, 1139, 1169. 
28. McVay D, Schiraldi V, Ziedenberg J. Treatment or incarceration? National and state findings on the efficacy and cost savings of drug treatment versus imprisonment. Washington, DC: Justice Policy Institute; 2004. http://www.justicepolicy.org/uploads/justicepolicy/ documents/04-01_rep_mdtreatmentorincarceration_ac-dp.pdf

29. Nicosia N, Macdonald JM, Arkes J. Disparities in criminal court referrals to drug treatment and prison for minority men. Am J Public Health. 2013;103(6):e1-8.

30. Hasan S. One Year Later: Gloucester's Opioid Program Inspires Policy Reform. Nonprofitquarterly.org. 2016. https://www.bing. $\mathrm{com} / \mathrm{cr}$ ?IG=2E205962335A4BCAAC6DBF7D16EA4AA6\&CID= 2A42F55DBCCB64DB1C3EFFC7BDCD6539\&rd=1\&h= WsnSt413juX6R3CTteNKIZ5rt3dPelH2KY0ClJZgkY\&v=1\&r= https $\% 3 \mathrm{a} \% 2 \mathrm{f} \% 2$ fnonprofitquarterly.org $\% 2 \mathrm{f} 2016 \% 2 \mathrm{f} 06 \% 2 \mathrm{f} 03 \%$ 2 fone-year-later-gloucesters-opioid-program-inspires-policyreform\%2f\&p=DevEx,5064.1.

31. Ghandnoosh N. Black lives matter: eliminating racial inequity in the criminal justice system. Washington, DC: The Sentencing Project; 2015. p. 1-29.

32. Cole DM. A case study "If they had a cure I would not take it": African American women living with HIV/AIDS. In: Thomas D, editor. Women's health: readings on social, economic, and political issues. Dubuque: Kendall Hunt Publishing Company; 2017. p. 491-5.

33. CDC National Center for Health Statistics. Health United States, 2011: With special feature on socioeconomic status and health. Hyattsville, MD 2012.

34. Shacham E, Basta TB, Reece M. Symptoms of psychological distress among African Americans seeking HIV-related mental health care. AIDS Patient Care STDs. 2008;22(5):413-21. https://doi.org/ 10.1089/apc.2007.0177.

35. Sniffen MJ. Prisons lacking mental health treatment. WashingtonPost.com. 2006. http://www.washingtonpost.com/wpdyn/content/article/2006/09/06/AR2006090601629 2.html.

36. Steinberg D, Mills D, Romano M. When did prisons become acceptable mental healthcare facilities? Law.Stanford.edu. https://law. stanford.edu/publications/when-did-prisons-become-acceptablemental-healthcare-facilities-2/.

37. NIDA. Comorbidity: addiction and other mental disorders. Bethesda, MD. 2011. https://www.drugabuse.gov/publications/ drugfacts/comorbidity-addiction-other-mental-disorders.

38. Pillai K, Rouse P, Mckenna B, Skipworth J, Cavney J, Tapsell $R$, et al. From positive screen to engagement in treatment: a preliminary study of the impact of a new model of care for prisoners with serious mental illness. BMC Psychiatry. 2016;16:9. http://bmcpsychiatry.biomedcentral.com/articles/ 10.1186/s12888-016-0711-2

39. Barham P. Closing the asylum: the mental patient in modern society. London: Penguin; 1997.

40. Hong Chui W, Kwok-Yin Cheng K. The mark of an ex-prisoner: perceived discrimination and self-stigma of young men after prison in Hong Kong. Deviant Behavior. 2013;34(8): 671-84.
41. New C. This is prison? 60 minutes goes to Germany. CBSNews.com. 2016. http://www.cbsnews.com/news/this-isprison-60-minutes-goes-to-germany/.

42. Travis NT. What we learned from German prisons. In: NYTimes.com; 2015. https://www.nytimes.com/2015/08/07/ opinion/what-we-learned-from-german-prisons.html? $\mathrm{r}=0$.

43. Bukten A, Lund IO, Rognli EB, Stavseth MR, Lobmaier P, Skurtveit S, et al. The Norwegian offender mental health and addiction study - design and implementation of a national survey and prospective cohort study. Substance Abuse: Research and Treatment. 2015;9(Suppl 2):59-66.

44. World Health Organization. The Madrid recommendation: health protection in prisons as an essential part of public health. Copenhagen: WHO Regional Office for Europe; 2009.

45. Hughes C, Stevens A. The effects of decriminalization of drug use in Portugal. The Beckley Foundation Drug Policy Programme White Paper. BeckleyFoundation.org 2007;1-10. https://core.ac. uk/download/pdf/91904.pdf

46. James DJ, Glaze LE. Mental health problems of prison and jail inmates. Bureau Justice Stat Spec Rep. 2006; https://www.bjs. gov/content/pub/pdf/mhppji.pdf

47. Falconer E, El-Hay T, Alevras D, et al. Integrated multisystem analysis in a mental health and criminal justice ecosystem. Health Just. 2017;5:4.

48. Redlich A, Steadman H, Monahan J, Robbins P, Petrila J. Patterns of practice in mental health courts: a national survey. Law Hum Behav. 2006;30(3):347-62.

49. Rosenberg CE. What is an epidemic? AIDS in historical perspective. Daedalus. 1989;118(2):1-17.

50. DuBois WEB. The Philadelphia negro. New York: Lippincott; 1899. p. 162.

51. Lebel TP. Invisible stripes? Formerly incarcerated persons' perceptions of stigma. Deviant Behav. 2012;33(2):89-107. https://doi.org/ 10.1080/01639625.2010.538365.

52. Corrigan PW, Watson AC. Understanding the impact of stigma on people with mental illness. World Psychiatry. 2002;1(1):16-20.

53. Schnittker J, John A. Enduring stigma: the long-term effects of incarceration on health. J of Health Soc Behav. 2007;48(2):115-30.

54. US. Title 18.Crimes and Criminal Procedure 18 USCA Section 2243.

55. ASA Series on How Race and Ethnicity Matter. Race, ethnicity, and the criminal justice system. American Sociological Association. 2007. http://www.asanet.org/sites/default/files/savvy/images/press/ docs/pdf/ASARaceCrime.pdf.

56. Nilsen E. N.H. in line to get piece of $\$ 1$ billion of drug treatment money passed by Congress. Concord Monitor. 2016. http://www. concordmonitor.com/with-strong-support-over-addiction-treatmentfunding-21st-century-cures-bill-heads-to-senate-6637937.

57. Centers for Disease Control and Prevention. Drug overdose death data. Retrieved 2017. https://www.cdc.gov/drugoverdose/data/ statedeaths.html.

58. Lawlor J. 21st Century Cures Act includes funding for opioid treatment programs. Press Herald 2016. http://www.pressherald.com/ 2016/12/07/21st-century-cures-act-includes-funding-for-opioidtreatment-programs/. 